\title{
PERFORMANSI WLAN KANTOR PUSAT PEMERINTAHAN KABUPATEN BADUNG
}

\author{
Linawati. ${ }^{1}$, Nyoman Gunantara ${ }^{2}$, I K A Riki Gunawan ${ }^{3}$
}

\begin{abstract}
WLAN has been implemented widely, including in public area and government office. Badung Regency office has got benefit from the technology in applying its egovernment services. However the WLAN performance in term of its QoS has not been evaluated after its installation. Then its delay, packet loss, throughput, and jitter were measured using Ekahau Heatmapper, Axence Nettols, Wi-Fi Analyzer, and Ubiquiti Unifi. The WLAN coverage area was calculated and analyzed. Generally, the performance is good. However there are areas in all 12 buildings in the offices that are needed more access points.
\end{abstract}

Intisari —Salah satu kemajuan utama di bidang telekomunikasi adalah penggunaan teknologi Wireless Local Area Network (WLAN). Pusat Pemerintahan (Puspem) Kabupaten Badung telah menerapkan teknologi ini untuk mengimplementasikan e-Government. Kinerja WLAN yang telah diimplementasikan tersebut perlu dianalisis apakah sudah optimal dalam menyediakan kualitas jaringan (Quality of Service - QoS) yang baik. Pengukuran tentang kualitas jaringan tersebut dilihat dari Delay, Packet loss, Throughput, dan Jitter dengan menggunakan software Ekahau Heatmapper, Axence Nettols, Wi-Fi Analyzer, dan Ubiquiti Unifi. Hasil pengukuran QoS didapatkan berikut pengaruh nilai redaman terhadap kualitas jaringan dan Coverage Area WLAN. Secara umum QoS WLAN di Puspem Kabupaten Badung baik, namun di beberapa area di seluruh gedung perlu dilakukan penambahan titik Access point.

\section{Kata Kunci - WLAN, QoS, Coverage Area}

\footnotetext{
${ }^{1}$ Dosen, Teknik Elektro dan Komputer Universitas Udayana, Kampus Bukit Jimbaran, Badung Bali. 80361, Tel. 0361703315 fax: 0361703315; e-mail: linawati@unud.ac.id

${ }^{2}$ Dosen Teknik Elektro dan Komputer Universitas Udayana, Kampus Bukit Jimbaran, Badung Bali. 80361, Tel. 0361703315 fax: 0361703315; e-mail: gunantara@unud.ac.id

${ }^{3}$ Mahasiswa, Teknik Elektro dan Komputer Universitas Udayana, Kampus Bukit Jimbaran, Badung Bali. 80361, Tel. 0361703315 fax:0361703315; e-mail: riki@gmail.com
}

\section{PENDAHULUAN}

Kantor Pusat Pemerintahan Kabupaten Badung saat ini memiliki 98 access point untuk fasilitas wireless LAN (WLAN) dengan bandwidth Internet $50 \mathrm{Mbps}$. Akses Internet dimanfaatkan untuk layanan e-government. WLAN atau hotspot di Pusat Pemerintahan Kabupaten Badung terdapat di setiap gedung, yang setiap lantainya memiliki 2 sampai 3 access point.

Jaringan Wireless LAN di Pusat Pemerintahan Kabupaten Badung saat ini memakai access point Ubiquiti UNiFi dengan frekuensi 2,4 GHz, serta menggunakan autentifikasi server dengan Sistem Operasi Windows, Ubiquiti UNifi dan Dialup admin. Sehingga dari sisi pengguna memiliki kemudahan dalam hal melakukan akses ke jaringan WLAN dan dari sisi administrator mempunyai media dalam memantau dan mengontrol pengguna yang terhubung ke jaringan serta dapat membatasi penggunaan bandwidth.

Pusat Pemerintahan (Puspem) Kabupaten Badung memiliki 12 gedung, di mana setiap gedung memiliki 3 lantai dan masingmasing lantai memiliki 12 sampai 18 ruangan. Sehingga total ruangan di Puspem Badung mencapai 640 ruang. Untuk itu performansi WLAN perlu dievaluasi dengan memperhatikan faktor area cakupan dan redaman setiap lantai. Penempatan access point tanpa perencanaan baik berdampak dengan adanya area blank spot, sehingga diperlukan pengukuran kembali untuk meminimalkan blank spot di Pusat Pemerintahan Kabupaten Badung. Dengan demikian penelitian ini bertujuan untuk mengevaluasi performansi WLAN di Pusat Pemerintahan Kabupaten Badung dari sisi Delay, Packet loss, Throughput, dan Jitter.

\section{II.PROPAGASI MULTIWALL}

Pemodelan Multi-wall memperhitungkan rugirugi linear yang sebanding dengan jumlah tembok yang dilewati oleh gelombang radio, seperti diperlihatkan pada gambar 1 [1]. 


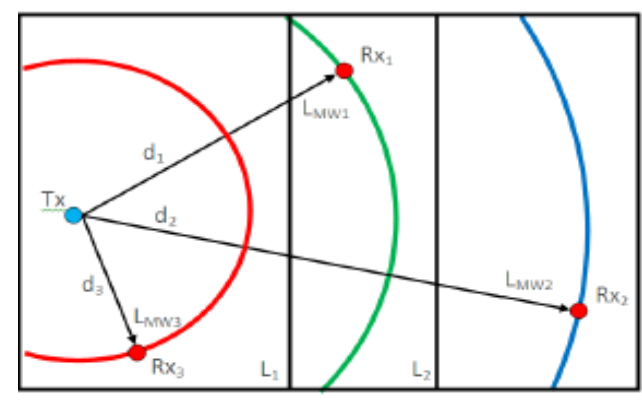

Gambar 1. Ilustrasi permodelan Multi-Wall

Persamaan matematis dari permodelan Multi-Wall [1] adalah sebagai berikut:

$$
\begin{aligned}
& L=L f s+L c+\sum_{i=1}^{I} k_{w i} L_{w i} \\
& L_{M W}(d)=L_{0}+10 \gamma \log (d)+\sum_{i=1}^{I} K_{w i} L_{w i}
\end{aligned}
$$

Di mana $\mathrm{L}_{0}$ adalah nilai referensi rugi-rugi pada jarak $1 \mathrm{~m}$ yaitu sebesar 40,05 dB. $\Upsilon$ adalah faktor eksponen Path loss yaitu 2, $d$ adalah jarak dalam satuan meter dan $\mathrm{L}_{\mathrm{i}}$ adalah faktor rugi-rugi dalam satuan $\mathrm{dB}$, yang ditimbulkan oleh dinding ke-i dan $\mathrm{M}$ adalah jumlah dinding di antara antena dan penerima.

\section{REDAMAN}

Setiap media transmisi memiliki redaman yang berbeda-beda, tergantung dari jenis dan bahan yang digunakan. Kekuatan sinyal yang ditransmisikan bisa mengalami pelemahan karena jarak yang jauh dan adanya media penghalang dalam bentuk apapun. Media transmisi yang digunakan adalah Access point (AP).

Untuk skenario dalam ruangan, node dalam jaringan ad hoc berada di dalam sebuah ruangan. Ruangan dipisahkan oleh dinding yang mungkin melemahkan sinyal dengan menghitung koefisien transmisinya. Kekuatan konsumsi daya transmisi dari satu node ke node lain di ruangan yang berbeda dapat ditentukan melalui persamaan (3) dengan mengetahui koefisien transmisi sebagai berikut.
$\operatorname{Pr}=\operatorname{PtGtGr}\left(\frac{\lambda}{4 \pi}\right)^{2} d^{-\alpha} 10^{\alpha \varphi / 10} \prod_{M=1}^{M}\left|\Gamma_{m}\right|^{2}$

Dimana $\Gamma$ dan $M$ menjadi koefisien transmisi dinding dan jumlah dinding masing - masing ruangan. Parameter yang berhubungan dengan penentuan redaman ditampilkan pada tabel 1 [2].

Tabel 1. Parameter Perhitungan Redaman

\begin{tabular}{|c|c|c|}
\hline Parameter & $:$ & Value \\
\hline Outdoor path loss exponent & $\alpha 0$ & 4 \\
\hline Indoor pathloss, exponent & $\alpha \mathrm{i}$ & 2 \\
\hline Ptandard deviation of shadowing & $\varphi$ & $8 \mathrm{~dB}$ \\
\hline Wall transmission coefficient & $\Gamma$ & 0,3 \\
\hline Threshold receive power & Pthd & $-50 \mathrm{dBm}$ \\
\hline Bandwidth & W & $20 \mathrm{MHz}$ \\
\hline Noise & No & $-101 \mathrm{dBm}$ \\
\hline Jumlah penghalang & $\mathrm{M}$ & $8 \mathrm{~dB}$ \\
\hline Power transmit & Pt & $4 \mathrm{~W}$ \\
\hline Transmit antenna gain & $\mathrm{Gt}$ & $2 \mathrm{~dB}$ \\
\hline Receive antenna gain & $\mathrm{Gr}$ & $2 \mathrm{~dB}$ \\
\hline Jarak antara access point dan client & $\mathrm{D}$ & $8-16 \mathrm{~m}$ \\
\hline
\end{tabular}

\section{PERHITUNGAN CAKUPAN AREA}

Untuk dapat mengetahui luas coverage AP maka harus diukur panjang diameter AP melalui perhitungan MAPL (Maximum Allowed Path Loss). MAPL adalah nilai redaman propagasi maksimum yang diperbolehkan agar koneksi antara pengguna dengan AP dapat berjalan dengan baik [3]. Perhitungan MAPL dilakukan dengan menggunakan persamaan (4) - (6).
MAPL $=$ EIRP - Margin - SRX
EIRP $=\mathrm{P}_{\text {Transmit }}-\mathrm{L}_{\text {Saluran }}+\mathrm{G}_{\text {Antena }}$
RSL $=\mathrm{EIRP}-\mathrm{L}+\mathrm{Gr}$ 


\section{ANALISIS PERFORMANSI WLAN}

Packet Loss, delay, jitter, dan throughput merupakan parameter kualitas layanan jaringan yang dievaluasi disini. Packet loss menggambarkan kondisi jaringan dimana paket hilang disebabkan antara lain oleh collision. Hal ini menyebabkan retransmission yang akan mengurangi efisiensi jaringan secara keseluruhan meskipun jumlah bandwidth cukup tersedia [4]. Sedangkan delay adalah waktu yang dibutuhkan data untuk menempuh jarak dari asal ke tujuan. Delay dapat dipengaruhi oleh jarak, media fisik, dan juga waktu proses di jaringan. Sedangkan jitter disebut juga variasi delay dan berhubungan erat dengan latency. Delay antrean pada switch dan router dapat menyebabkan Jitter. Untuk mendapatkan nilai kualitas layanan jaringan yang baik, maka nilai Jitter harus dijaga seminimum mungkin. Adapun Throughput merupakan kecepatan transfer data efektif, yang diukur dalam bit per second (bps). Throughput merupakan jumlah total kedatangan paket yang sukses, yang diamati pada tujuan selama interval waktu tertentu dibagi oleh durasi interval waktu tersebut.

Pada penelitian ini dilakukan analisis performansi dengan melakukan perhitungan dan pengukuran. Adapun langkah langkah yang dilakukan sebagai berikut.

- Melakukan pengambilan data melalui pengukuran AP (Access Point) di 32 lantai menggunakan software [5, 6]. Pengukuran dilakukan pagi, siang, dan sore selama 4 hari dalam seminggu. Sehingga didapatkan perbandingan data setiap waktunya.

- Melakukan perhitungan MAPL yang diperbolehkan untuk mendapatkan jarak maksimum yang bisa diterima agar konektivitas pengguna dan AP baik.

- Hitung luas area bangunan dengan luas cakupan AP untuk mendapatkan jumlah AP yang dibutuhkan.

- Pengukuran redaman dari setiap penghalang yang menghalangi sinyal dari pemancar (AP) ke arah penerima (pengguna) seperti dinding beton, sekat lunak dan pintu kayu.

- Letakkan pemancar pada posisi terjauh dari penerima, lalu ukur batas sinyal yang diterima, apakah sudah sesuai dengan standar minimum yang ditentukan.

- Jika batas minimum dicapai maka di situlah AP tambahan dipasang.

Pusat Pemerintahan Kabupaten Badung dengan 13 gedung dan total 32 lantai memiliki nilai MAPL sebagai berikut.

Margin = Fading Margin $=10 \mathrm{~dB}$

SRX= Sensitifitas penerima =MCS15 @ -70 dBm Frekuensi 802.11b/g/n (spesifikasi pada alat)

MAPL $=20 \mathrm{dBm}-0,5 \mathrm{~dB}+6 \mathrm{~dB}-10 \mathrm{~dB}-(-70 \mathrm{dBm})$

MAPL $=85,5 \mathrm{~dB}$

MAPL $=\mathrm{L}=$ LFS $+(2 \times 10)+(3 \times 5)$

LFS $=$ MAPL $-35=85,5-35=50,5 \mathrm{~dB}$

$50,5=20 \log 100,48 d$ $\mathrm{d}=175,26 \mathrm{~m} /$ access point

Luas coverage AP $=550,83 \mathrm{~m}^{2}$

Dengan demikian luas area cakupan AP WLAN sebesar $550,83 \mathrm{~m}^{2}$ dengan luas setiap lantai rata-rata sebesar $3.256 \mathrm{~m}^{2}$. Nilai redaman hasil perhitungan dan pengukuran ditampilkan pada tabel 2. Nilai redaman tersebut diperoleh dengan menghitung daya pancar penerima dengan menggunakan persamaan (3) sebagai berikut.

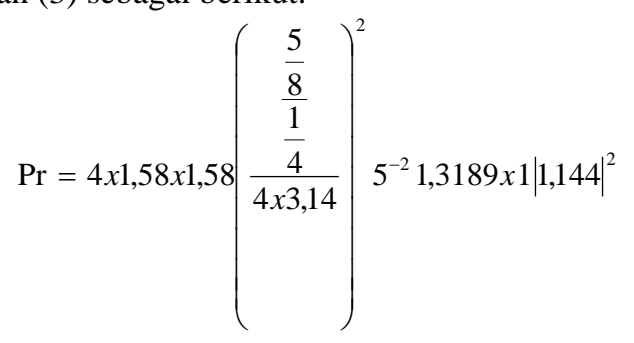

$\operatorname{Pr}=-36,98 \mathrm{dBm}$

Tabel 2. Nilai redaman penghalang

\begin{tabular}{|l|l|l|l|l|}
\hline \multicolumn{5}{|c|}{ Nilai rendaman l penghalang } \\
\hline titik & $\begin{array}{l}\text { Jarak } \\
\left(d^{-\alpha}\right)\end{array}$ & $\begin{array}{l}\text { Shadouing } \\
\left.10^{-9 / 10}\right)\end{array}$ & $\begin{array}{l}\text { hasil } \\
\text { perhitungm } \\
(\mathrm{dRm})\end{array}$ & $\begin{array}{l}\text { hasil } \\
\text { pengukuran } \\
\text { (dRm) }\end{array}$ \\
\hline 1 & $5 \mathrm{~m}$ & 1,3189 & $-36,98$ & -40 \\
\hline 2 & $7 \mathrm{~m}$ & 3,3464 & $-35,37$ & -35 \\
\hline 3 & $8 \mathrm{~m}$ & 1,7492 & $-39,58$ & -45 \\
\hline 4 & $4 \mathrm{~m}$ & 1,2208 & $-34,81$ & -38 \\
\hline 15 & $5 \mathrm{~m}$ & 2,0625 & $-34,43$ & -42 \\
\hline 6 & $6 \mathrm{~m}$ & 1,2295 & $-38,53$ & -46 \\
\hline 7 & $8 \mathrm{~m}$ & 1,7258 & $-39,58$ & -40 \\
\hline 8 & $7 \mathrm{~m}$ & 4,8563 & $-33,66$ & -39 \\
\hline 9 & $8 \mathrm{~m}$ & 1,2569 & $-40,96$ & -50 \\
\hline 10 & $9 \mathrm{~m}$ & 2,4597 & $-38,86$ & -40 \\
\hline 11 & $7 \mathrm{~m}$ & 1,7516 & $-38,23$ & -42 \\
\hline 12 & $5 \mathrm{~m}$ & 1,1442 & $-36,98$ & -45 \\
\hline 13 & $6 \mathrm{~m}$ & 1,4474 & $-37,69$ & -52 \\
\hline 14 & $7 \mathrm{~m}$ & 1,2481 & $-39,58$ & -44 \\
\hline 15 & $6 \mathrm{~m}$ & 1,3832 & $-37,95$ & -50 \\
\hline
\end{tabular}

Coverage area sebelum di redesign sebesar 55,14\% dan setelah di redesign menjadi 99,84\% Sehingga tidak dilakukan perubahan letak dari access point. Access point yang terpasang sebanyak 97 access point yang dimana setiap lantai pada setiap gedung Pusat Pemerintahan Kabupaten Badung terpasang sebanyak 2-4 access point. 


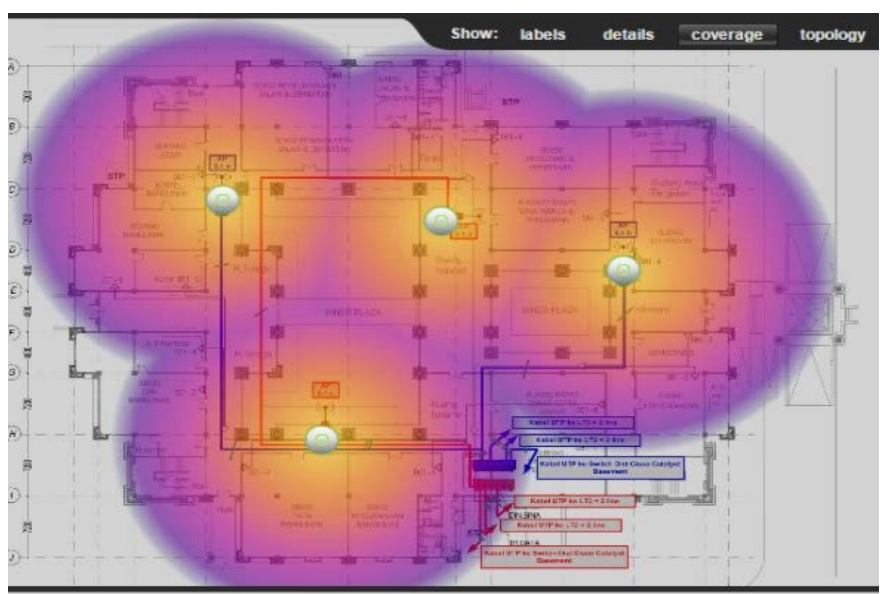

Gambar 3. Coverage area WLAN di gedung 9 sebelum redesign

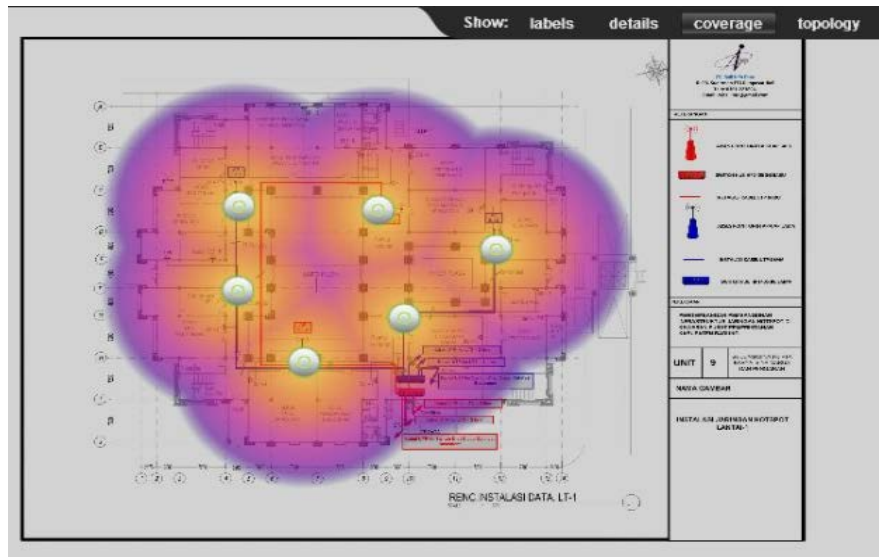

Gambar 4. Coverage area WLAN di gedung 9 setelah redesign

Penambahan access point dilakukan pada seluruh gedung dikarenakan coverage area wireless kurang dari 70\%. Sehingga jangkauan sinyal Wi-Fi tidak dapat ter cover secara menyeluruh, maka dilakukan penambahan access point sebanyak 2-4 access point dengan jumlah access point keseluruhan gedung setelah redesign sebanyak 186 buah.

Tabel 3, 4, dan 5 menampilkan nilai QoS yang didapatkan pada setiap lantai di seluruh gedung di Pusat Pemerintah Kabupaten Badung berupa packet loss, delay, Jitter, dan throughput dengan menggunakan 5 situs yaitu Facebook, detik.com, youtube, google, dan kompas.com dengan jarak 8$12 \mathrm{~m}$ dari access point.

Tabel 3. Hasil pengukuran Delay

\begin{tabular}{|l|l|l|l|l|}
\hline Situs & $\begin{array}{l}\text { Min } \\
(\mathrm{ms})\end{array}$ & $\begin{array}{l}\text { Max } \\
(\mathrm{ms})\end{array}$ & $\begin{array}{l}\text { Rata- } \\
\text { rata } \\
\text { delay } \\
\text { (ms) }\end{array}$ & ITU-T \\
\hline www.detik.com & 20,52 & 530,18 & 47,52 & $\begin{array}{l}\text { Sangat } \\
\text { bagus }\end{array}$ \\
\hline www.youtube.com & 35,58 & 482,26 & 58,03 & $\begin{array}{l}\text { Sangat } \\
\text { bagus }\end{array}$ \\
\hline
\end{tabular}

\begin{tabular}{|l|l|l|l|l|}
\hline www.facebook.com & 20,52 & 551,58 & 91,46 & $\begin{array}{l}\text { Sangat } \\
\text { bagus }\end{array}$ \\
\hline www.kompas.com & 27,35 & 527,6 & 57,2 & $\begin{array}{l}\text { Sangat } \\
\text { bagus }\end{array}$ \\
\hline www.google.com & 33,12 & 501,83 & 59,67 & $\begin{array}{l}\text { Sangat } \\
\text { bagus }\end{array}$ \\
\hline
\end{tabular}

Rata-rata nilai Packet Loss pada setiap situs sangat bagus di mana rata-rata persentase Packet Loss tidak lebih dari 8\%, sehingga rata -rata dari nilai delay tidak lebih dari $100 \mathrm{~ms}$ yang di mana standarisasi nilai QoS menyatakan sangat bagus.

Tabel 4. Hasil pengukuran Packet Loss

\begin{tabular}{|c|c|c|c|}
\hline \multirow[b]{2}{*}{ DNS Name } & \multicolumn{3}{|l|}{ Packet } \\
\hline & Sent & Loss & $\begin{array}{l}\% \\
\text { loss }\end{array}$ \\
\hline www.detik.com & 206,53 & 11,69 & 5,49 \\
\hline $\begin{array}{l}\text { Www.youtube.co } \\
\text { m }\end{array}$ & 206,58 & 9,69 & 4,49 \\
\hline $\begin{array}{l}\text { www.facebook.c } \\
\text { om }\end{array}$ & 206,55 & 12,43 & 5,98 \\
\hline $\begin{array}{l}\text { Www.kompas.co } \\
\underline{\underline{m}}\end{array}$ & 206,23 & 16,75 & 7,92 \\
\hline www.google.c & 206,58 & 13,98 & 6,55 \\
\hline
\end{tabular}

Pada nilai Jitter didapatkan rata-rata Jitter sebesar 0,311 ms. Sehingga dalam kategori degradasi termasuk dalam kategori sangat bagus ( $0 \mathrm{~s} / \mathrm{d} 75 \mathrm{~ms}$ ), semakin besar nilai Jitter maka semakin buruk kualitas jaringan internet tersebut.

Tabel 5. Hasil pengukuran Jitter

\begin{tabular}{|l|l|l|l|}
\hline Interval & $\begin{array}{c}\text { Transfer } \\
(\text { Kbps })\end{array}$ & $\begin{array}{c}\text { Bandwidth } \\
(\mathrm{Mbps})\end{array}$ & $\begin{array}{c}\text { Jitter } \\
(\mathrm{ms})\end{array}$ \\
\hline $0,0-1,0$ & 128 & 1,05 & 0,345 \\
\hline $1,0-2,0$ & 128 & 1,05 & 0,331 \\
\hline $2,0-3,0$ & 128 & 1,05 & 0,136 \\
\hline $3,0-4,0$ & 128 & 1,05 & 0,406 \\
\hline $4,0-5,0$ & 128 & 1,05 & 0,383 \\
\hline $5,0-6,0$ & 129 & 1,06 & 0,249 \\
\hline $6,0-7,0$ & 128 & 1,05 & 0,507 \\
\hline $7,0-8,0$ & 128 & 1,05 & 0,270 \\
\hline $8,0-9,0$ & 128 & 1,05 & 0,253 \\
\hline $9,0-10,0$ & 128 & 1,05 & 0,257 \\
\hline $0,0-10,0$ & 1.25 & 1,05 & 0,287 \\
\hline
\end{tabular}

Pada throughput didapatkan nilai rata-rata sebesar 5,617 Mbps. Sehingga kualitas dari setiap situs tersebut terdegradasi bagus dengan jarak 8-12 m dari access point ke penerima. Sehingga kualitas jaringan tetap baik saat jangkauan sinyal pemancar pada titik terjauh, seperti diperlihatkan pada gambar 5. 


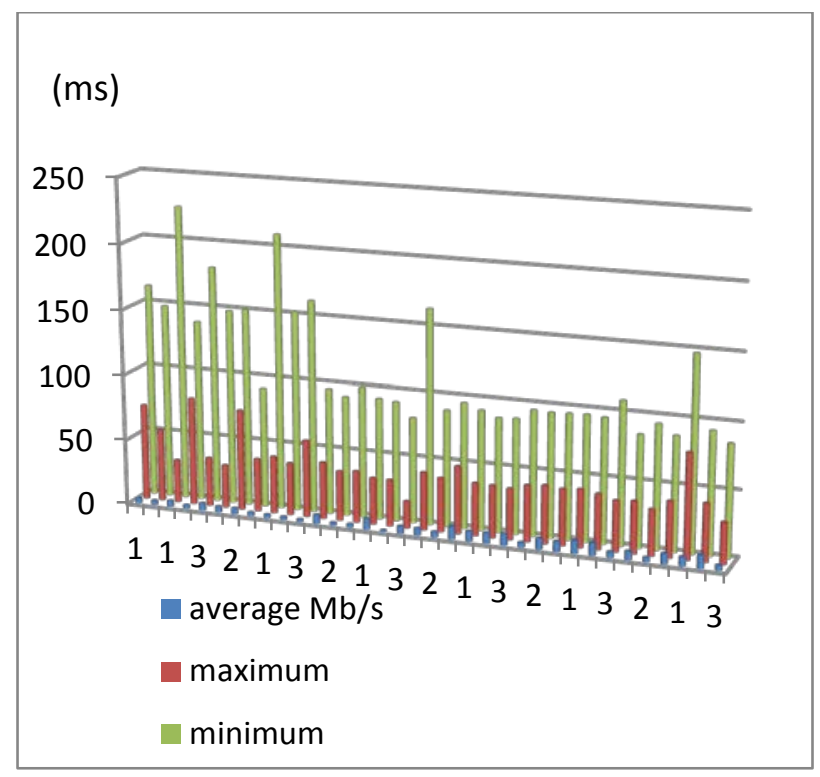

Gambar 5. Throughput

\section{KESIMPULAN}

Nilai QoS dinyatakan sangat bagus dimana nilai Delay tidak lebih dari 100 ms, rata-rata persentase Packet Loss tidak lebih dari 8\%, rata-rata nilai Throughput sebesar 5,617 Bit/s dan rata-rata Jitter sebesar 0,311ms.

Coverage area sebelum di redesign sebesar 55,14\% dan setelah di redesign menjadi 99,84\%. Sehingga tidak dilakukan perubahan letak dari access point. Sinyal Wi-Fi yang tidak dapat ter- cover secara menyeluruh, dilakukan penambahan access point sebanyak 2-4 access point dengan jumlah access point keseluruhan gedung setelah redesign sebanyak 186 buah.

\section{DAFTAR PUSTAKA}

[1] Faisol RM, Santoso.2012. Simulasi Cakupan Area Sinyal WLAN 2.4 GHz pada Ruangan. Semarang : Universitas diponogoro.

[2] Gerlin Manurung D, Mubarakah. 2013. Analisis Coverage Area Wireless Local Area Network (WLAN) 802.11b dengan menggunakan Simulator Radio Mobile. Sumatra Utara:Vol1 no 3.

[3] Gomudha. 2012. Gambaran Umum Kabupaten Badung dan Pemerintahan Mangupraja. http://www.badungkab.go.id/. Diakses tanggal 15 agustus 2014.

[4] N. Gunantara and G. Hendrantoro: Multi-Objective Cross-Layer Optimization with Pareto Method for Relay Selection in Multihop Wireless Ad hoc Networks, WSEAS Transaction on Communications, Vol. 12, Issue 3, 2013.

[5] Hereby, UBIQUITI NETWORK, declares that this UBIQUITI NETWORK device, is in compliance whit the essential requirement and other relevant provisions of Directive 1999/5/EC.

[6] Kurnia P,Kartika, Budi Santoso T,Adi Siswandari.2010.Optimasi Penataan Sistem Wi-Fi di PENS-ITS dengan Menggunakan Metode Algoritma Generator 